\title{
Presupposition, assertion and the encoding of evidentiality in political discourse
}

\author{
Viviana Masia (Roma)
}

\begin{abstract}
The way linguistic messages are "packaged" in political discourse often reflects evidentiallybased criteria and, notably, the intention of the politician to make his epistemic commitment more or less manifest in relation to the type of content proffered to the receiver. The present paper analyzes the evidential function of presupposition and assertion (apud Masia 2017) in a corpus of English, French and Italian political speeches, with the aim of highlighting how these units of information structure are strategically resorted to by politicians to modulate their commitment to more or less challengeable types of content. Data show that more challengeable content types (i. e. attacks and self-praises) are likely to be encoded as presupposition, which reduces the speaker's commitment to their truth; in contrast, less challengeable content types (i. e. neutral/informative and stance-taking) are more likely to be asserted, with the speaker showing stronger commitment to their truth.
\end{abstract}

\section{$1 \quad$ Introduction}

\subsection{Information source and speaker attitude evidentiality}

Since Boas's seminal reports (Boas 1900, 1910) on how the source of information is marked in some languages of the Americas, evidentiality has become the plank of much theoretical and typological research (Chafe/Nichols 1986; Willett 1988; Aikhenvald 2004). As already addressed in much earlier and recent accounts, evidential systems in the world's languages are extremely diversified and display different levels of complexity, with twofold up to six-fold paradigms (Aikhenvald 2004). In some recent contention (Aikhenvald 2004; Cornillie 2009), the linguistic coding of information source has been characterized as the sole function of evidential markers, distinct from expressions whose function is precisely to signal the speaker's attitude to information, a meaning typically associated with epistemic modality. Already in Friedman's works on Balkan evidentials (Friedman 1986), it emerged that in languages such as Bulgarian, Albanian and Macedonian, evidentiality systems conveyed speaker attitude meanings, hinting at stronger or weaker speaker commitments to the truth of a proposition. Building on this multi-faceted behavior of evidentials in the world's languages, Chafe/Nichols (1986) put forth a distinction between a "narrow" and a "broad" type of evidentiality, the former marking the source of information proper, the latter the speaker's attitude to the truth of a proposition. In the present paper, I will comply with this characterization of evidentiality, with the view to highlighting the non inter-independence of the narrow and broad scope of evidentials, as the 
adoption of an attitude or perspective on knowledge also entails providing cues on who is the source of that knowledge. Below, some examples of information source and speaker attitude evidentials in typologically different languages are provided.

The Wanka Quechua examples in (1) illustrate a case of narrow evidentiality encoded through a tripartite system with direct, conjectural/inferential and indirect/reportative evidential markers (Aikhenvald 2004: 43).

\section{DIRECT EVIDENTIALITY}

a. Chay-chruu-mi achk wamla-pis walashr-pis alma-ku-lkaa-ña

This-loc-dir.evid many girl-too boy-too bathe-refl.-imprf.plnar.pst

'Many girls and boys were swimming (I saw them).'

INFERENTIAL/CONJECTURAL EVIDENTIALITY

b. Daañu pawa-shra-si ka-ya-n-chr-ari

field finish-partitive-eventive be-imprf-3-infer-emph

'It (the field) might be completely destroyed (I inferred).'

INDIRECT/REPORTATIVE EVIDENTIALITY

$\begin{array}{lll}\text { c. Ancha-p-shi } & \text { wa'a-chi-nki } & \text { wamla-a-ta } \\ \text { too.much-gen-report. } & \text { cry-caus-2 } & \text { girl-1p-acc }\end{array}$

'You make my daughter cry too much (I've been told).'

The direct evidential - $m i$ in (1a) indicates that the proposition that many boys and girls were swimming is first-hand evidence of the speaker. In (1b), the inferential marker chr-classifies the probability of the field being destroyed as indirect evidence, which the speaker arrived at on the basis of situationally available cues. In (1c), -shi signals that the state of affairs uttered is a second-hand report and that someone else is the direct source of it (for other evidential markers, cf. Faller 2002, 2011).

As already said, systems of broad evidentiality were first found in the Balkan linguistic area and, particularly, in Bulgarian, Macedonian and Albanian (Friedman 1986). In these languages, the speaker's attitude to truth is encoded by definite and indefinite past forms of verbs. Definite forms express a stronger commitment of the speaker to the truth of a proposition, while indefinite forms mark a weaker commitment. For example, in (2), the speaker presents the state of affairs as if he indeed had adequate evidence of its truth, although he may in fact have not witnessed it at all.

(2) Beše

Be.pluprf.definite(she)

'(She) was there.' tamo

there 
Friedman remarks that what differentiates Balkan evidentiality from other strategies of evidential marking in the world's languages is the fact that Balkan perfective forms are not dedicated evidential markers, but rather "co-opted" strategies existing for the other non evidential purposes.

These forms are thus not special evidential forms but rather forms contextually capable of expressing evidentiality. In pluperfect forms which developed later, during or after the rise of evidentiality, it appears that an evidential meaning can be treated as invariant, though it need not be treated as a separate grammatical category.

(Friedman 1986: 169)

The hypothesis that evidentiality could find encoding in linguistic devices generally devoted to non-evidential functions has also been addressed by Aikhenvald (2004) who distinguishes between "evidential markers" proper and "evidential strategies". While the former have raised in languages to mark evidential meanings only, the latter can be occasionally targeted at expressing evidentiality in specific communicative situations. Generally speaking, evidentiality marking is believed to comply with the need of being precise about one's source of information or reliability of knowledge. Despite the obligatory nature of evidential marking in some languages, though, the actual possession of knowledge as well as of adequate evidence of truth is not a sine qua non condition for a correct use of evidentials. As also noticed by Aikhenvald (2004: 98): "one can deliberately use the wrong evidential with the correct information", and so the ties between the use of evidential markers and the real epistemic status of contents are much looser than commonly believed (Masia 2017: 62). Among other reasons, this can happen for deceptive purposes and for the speaker's desire to save his own "face" (Goffmann 1981) in risky interactions. This means that evidentiality marking ends up being a mere system of cues at different knowledge states and commitments in a conversation. If, on the one hand, a "wrong" use of evidentials can make the speaker a potential lier or an uncooperative communicator, on the other, it can prove to be particularly effective in constructing ideas and convictions in the addressee's mind thus manipulating his representation of truth. This use of language is not uncommon in many domains of public communication; notably, political propaganda is massively characterized by its presence, which is why it constitutes a fertile testing ground to study evidentiality phenomena and their relation to truth value assessments (cf. "Evidence and evidentiality are inextricably tied to social, cultural and even political relationships among participants"; Fox 2001: 169).

The present paper is concerned with a special case of broad evidentiality; more specifically, it addresses evidentiality marking in political discourse looking at how it is encoded through the presupposition and the assertion of information in a sentence. In the framework adopted in this work, the presupposition-assertion dichotomy is taken to inhere in the domain of micropragmatics and, precisely, in the linguistic level known as Information Structure (Cresti 1987; Lambrecht 1994; Gundel/Fretheim 2004), referring to the way(s) in which sentence contents are distributed according to degrees of informational prominence. Integrated approaches to evidentiality and information structure are still at dawn (Faller 2002; Masia 2017a, 2017b) and the present study is an attempt to contribute to existing contention with a further body of evidence from political communication, which might add grounds to current reflections on the evidential status of information units. In the view herein presented, presupposition and assertion hint at 
different degrees of speaker commitment to the truth of a proposition, with presupposition signaling a weaker commitment than assertion. (For a more extensive account on the relation between presupposition and commitment, cf. Sbisà (2007) and Mazzarella et al. (2018). Particularly, see Mazzarella et al. (2018) for an interesting analysis of presuppositions are creating a "collective voice" in conversation, which accordingly leads the speaker to not take direct responsibility for the presupposed content.) $)^{1}$ To delve into this interaction, the present study will also consider the "content type" variable, namely the particular purpose with which a content is asserted or presupposed in an utterance. As the analysis will show, politicians' use of presuppositions and assertions seems to be sensitive to the function and truth value some content has in a given linguistic context.

The paper is structured as follows. Section 2 briefly introduces the presupposition-assertion distinction and outlines their evidential function of marking two different epistemic stances in communication. Section 3 lays out the parameter I called Communicative Function, indicating the type of content conveyed as presupposition and/or assertion. Section 4 presents the data gathered from a corpus of English, French and Italian political speeches and describes the methodology applied. A discussion of the results is reported in Section 5.

\section{Presupposition and assertion as evidential strategies}

\subsection{Presupposition and assertion: an overview}

In a Stalnakerian perspective, presupposition can be laid out as information taken for granted by the speaker as belonging to the common ground of the receiver. In ordinary conversations, presuppositions are projected by means of lexical expressions or syntactic constructions, for this reason called presupposition triggers. In (3), a list of some of the most common presupposition triggers is provided (Fillmore 1971; Kiparsky/Kiparsky 1971; Sbisà 2007; Lombardi Vallauri 2009):

\section{DEFINITE DESCRIPTION}

a. The candy box is on the TV shelf.

\section{ITERATIVE ADVERB}

b. Your dog has broken my vase again.

\section{ADDITIVE ADVERB}

c. Jane also drinks milk for breakfast.

Change of STATE Verb

d. Mark keeps on making noise at night.

FACTIVE PREDICATE

e. It's not fair that bad students are left unpunished.

\footnotetext{
${ }^{1}$ Elsewhere (Masia 2017a), it is contended that this property of presupposition is at the very basis of its unchallengeability in discourse, in that, the more commitment is shared between speaker and hearer, the less likely the hearer will put the presupposition into discussion
} 


\section{ADVERBIAL SUBORDINATE CLAUSES}

f. When my daughter graduated, we bought her a new car.

\section{WH-QUESTIONS}

g. Who broke my new lamp?

\section{ALTERNATIVE QUESTIONS}

\section{h. Do you prefer whiskey or an Irish coffee?}

In (a), the definite description the candy box presupposes the existence of a candy box. In (b), the iterative adverb again presupposes that the dog has broken the vase before. In (c), the additive adverbial also conveys the presupposition that Jane drinks something else for breakfast besides milk. The change of state verb keep on, in (d), entails that Mark has been making noise before the utterance time. In (e), the factive predicate It's not fair presupposes that the bad students are not punished. In (f), the subordinate clause presents as already known information that the speaker's daughter graduated, while in (g) and (h) it is presupposed, respectively, that someone broke the new lamp and that the addressee wants to drink something.

As suggested by its etymology (latin prae-supponere 'to suppose in advance'), in presupposing some information, the speaker assumes or, better said, treats that information as already holding in the common ground of the conversation, which means that a presupposition simply recalls information already possessed by the receiver prior to a communicative act. Nonetheless, presupposition triggers are often used to convey new presuppositions as well. In such a case, the presupposition is said to be "accommodated" by the receiver (Lewis 1979), in the sense that his mental representation of the discourse model must be updated with the meaning carried by the new presupposition. It must be highlighted that presupposition accommodation comes with a tacit acceptation of the presupposed content on the part of the addressee. In fact, in taking some content for granted, the speaker induces his interlocutor not to sound out its truth value thoroughly and shift his attention to another sentence part. This is one of the reasons why new or informative presuppositions may also be efficient means of persuasion:

Sometimes, an informative presupposition also becomes persuasive as it leads the audience to see the world the way the author of the text sees it. This is because presupposition stealthily introduces dubious notions, tendentious interpretations and value judgments keeping them from critical discussion.

(Sbisà 2007: 90) $)^{2}$

Assertion belongs to that category of speech acts (Searle 1969) through which the speaker manifests his belief and commitment to the truth of a proposition.

By the very act of making an assertion, the communicator indicates that she is committing herself to providing the addressee with genuine information, and she intends his recognition of this commitment to give him a motive for accepting a content that he would not otherwise have sufficient reasons to accept.

(Sperber et al. 2010: 366)

\footnotetext{
2 Original text: "A volte la presupposizione informativa diventa anche persuasiva, poiché spinge il pubblico a vedere il mondo nel modo voluto dall'autore del testo, perché introduce di soppiatto, e impedendone la discussione, entità dubbie, interpretazioni tendenziose, criteri di valore".
} 
The belief state is however not a default property of assertions, since also propositions not believed as true by the speaker can be asserted. A lazy child may lie to his mother saying

(4) I have a terrible sorethroat.

when in fact he is simply unwilling to go to school. In this sense, assertions can be defined as communicative acts with which we dispense hints at "impressions of belief" (cf. "A man makes an assertion if he says something in such a manner as deliberately to convey the impression of saying it with the overriding intention of saying something true"; Dummett 1981: 300).

In everyday conversations, assertion takes the form of indefinite descriptions (5a) (especially when embedded in presentative constructions), syntactically independent clauses (5b) and nonrestrictive relative clauses $(5 \mathrm{c})$, among others.

(5a) There is a candy box on the TV shelf.

(5b) Your dog has broken my vase.

(5c) The onions, which you put in the fridge, come from Calabria.

We have seen that informative presuppositions update the receiver's common ground just like assertions do. However, if a presupposition induces the receiver to accept a proposition as true, with no further truth value verification, assertion makes the updating process more conscious and with an in-depth evaluation of its meaning on the part of the receiver. This is also what makes it a more challengeable communicative act, because more attention is devoted to its full encoding and its truth is evaluated prior to its integration in the mental representation of the ongoing discourse (Lombardi Vallauri 2016).

\subsection{Assertion and presupposition as evidential strategies}

The examples of narrow and broad evidentiality in (1) and (2), respectively, epitomize cases of overtly grammaticalized evidential meanings. Recent typological and discourse-based studies (Faller 2002, Murray 2010) have gathered a cogent body of evidence on how evidential meanings may also arise from the use of particular speech acts or from expectations on the construction of informational categories as the conversation unfolds (Saussure 2011; Masia 2017). In this latter case, evidentiality, whether narrow or broad, often does not receive overt superficial marking. Rather, it can be said to be pragmatically-inferred. This hypothesis leads to assume that if overtly grammaticalized evidentiality is only characteristic of some languages, pragmatically-inferred evidentiality is a language-universal property, since all languages are endowed with classes of speech acts and patterns of information structure associated with the speaker's choice to perspective information in some way and modulate his commitment to its truth. In this section, I will discuss some data that lend support to an evidential intepretation of presupposition and assertion and, more precisely, as two manifestations of a pragmatically-inferred evidentiality.

In a field work study on Cuzco Quechua evidentials, Faller (2002) observed that in this language also evidentially unmarked assertions can convey meanings of direct evidentiality. Just like in its Wanka variety, also Cuzco Quechua has direct, reportative and inferential evidentials (among other markers). In this language, the absence of evidential markers can however be 
classified as an evidential strategy, since plain assertions can be used to convey first-hand experience. Faller put forth this interpretation by asking her informants to judge the naturalness of the sentences in (6) and (7).

$\begin{array}{llll}\text { \#Para-sha-n-mi, } & \text { ichaqa } & \text { mana } & \text { crei-ni-chu } \\ \text { Rain-PROG-3-mi } & \text { but } & \text { not } & \text { believe-1-NEG }\end{array}$

'It is raining (I saw it), but I don't believe it.'

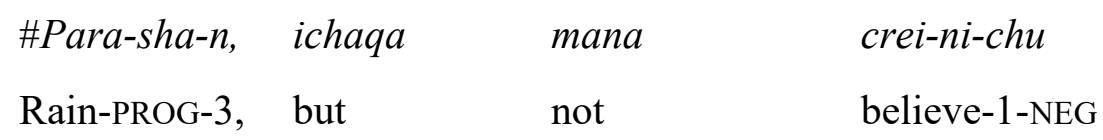

'It is raining, but I don't believe it.'

Both the assertion with the direct evidential - $m i$ and its unmarked version in (7) contain a contrastive clause negating the speaker's belief attitude to the truth of the preceding proposition. Faller used these retraction tests to verify how strong the speaker's commitment is perceived by the interlocutor. She observed that both sentence types were deemed infelicitous by her Quechua speakers. However, while in (6) the unacceptability hangs on the wrong use of an evidential marker, in (7), it is mainly driven by the misuse of an assertive speech act. She explains the anomaly stemming from (7) drawing on Vanderveken's account (1990: 117-118) according to whom "all assertive illocutionary forces have the sincerity condition that the speaker believes the propositional content". Therefore, denying the truth of what has been asserted gives rise to what she calls a Moore's paradox: "It is paradoxical to try to perform an illocutionary act and to deny simultaneously one of its sincerity conditions." (Vanderveken 1990: 118). Faller also remarks that if in cases of $m i$-marked sentences evidentiality is "grammatically" encoded, with unmarked plain assertions evidentiality is "implicated", which means that the evidential function of assertion is derived through implicatural inference and, precisely, through the implicit assumption that the speaker is complying with the sincerity condition of assertive illocutionary forces and with a believing attitude towards the expressed proposition.

In the same way, with presupposition the reaffirmation or denial of its truth would result in an unfelicitous sentence. Kiparsky/Kiparsky (1971) noticed this restraint with factive propositions and with definite phrases. In both (8a) and (8b), it is presupposed that John is ill by means of a factive-dependent declarative clause and a complex definite phrase. The status of taken for granted information makes this proposition incompatible with presentational expressions (8a) or with truth assertions $(8 \mathrm{~b})$.

(8a) *The fact that John is ill turns out.

(8b) *John's being ill is true/is false.

If some presupposed content must be taken as true by both speaker and receiver, its combination with predicates whose meaning is to present it as true or as novel information ends up in a useless and contradictory conversational move. In fact, what happens in (8a) and (8b) is that the speaker is informing the receiver about a truth which he already possesses (because shared in advance) with the result of bringing about no actual update of his mental model of discourse (In cooperational terms, this would amount to flouting the Gricean maxim of Quantity since the 
speaker is not being informative and is not relevantly contributing to the development of the communicative exchange.) As also remarked by Stalnaker (1978):

A speaker should not assert what he presupposes to be true, or what he presupposes to be false.

Given the meaning of presupposition and the essential effect ascribed to the act of assertion, this should be clear. To assert something incompatible with what is presupposed is self-defeating: one wants to reduce the context set, but not eliminate it altogether. And to assert something which is already presupposed is to attempt to do something that is already done.

(Stalnaker 1978: 325)

These properties of assertion and presupposition provide some grounding to further assess their correlation to two different perspectives that speakers can take in an interaction. I will flesh out this reflection drawing on a classification of epistemic stances proposed by Mushin (2001). In a comparative study on narrative retelling in Macedonian, Japanese and English, Mushin (2001) pinned down five different epistemological ${ }^{3}$ stances that can be taken by speakers in describing states of affairs. These are the personal experience stance, the reportive stance, the inferential stance, the imaginative stance and the factual stance. Two stances of her taxonomy will be at issue in this section, namely personal experience and factual stance. Mushin describes the adoption of a personal experience epistemic stance as involving the representation of information as "the product of the conceptualizer's direct and conscious perceptual experience. In many cases, the speaker is the only person who has access to the truth of the information. [...] these are contexts where the conceptualizer has witnessed an externally perceivable event" (Mushin 2001: 59). She also notices that one of the ways in which a personal experience epistemic stance can be linguistically realized is through the mention of private states and speaker intentions. We have seen before that a cooperative use of assertion comes with the assumption that (a) the speaker can be held responsible for the truth of the asserted proposition, and (b) that he is conveying that proposition as his main communicative intention in the ongoing interaction. Now, to me, the expectation of the speaker's having witnessed the state of affairs described is what equates a personal experience stance to the function of assertive speech acts, namely that of tying the speaker to the truth of the information conveyed. Indeed, if assertion entails that the speaker has adequate evidence for a proposition, it follows that the perspective it codifies is more akin to that encoded by direct and first-hand evidentials. Personal experience stance can thus be characterized as a particular type of broad evidentiality, and assertion can be seen as one of its grammatical (and pragmatic) manifestations.

When the speaker's intention is to leave the information source unexpressed, he may choose to adopt a factual epistemic stance. According to Mushin, this stance is normally taken by speakers when some exchanged information is believed to be shared in advance by everybody, and so any explicit indication of the source is not relevant.

Adoption of a factual epistemological stance is reflected in the absence of any representation of the source of information (and its status) in the construal. Adoption of a factual epistemological stance typically implies either that the information is assumed to be known by everyone in the

\footnotetext{
${ }^{3}$ From now on, I will use the term "epistemic" in place of "epistemological", this latter being more closely associated with the disciplinary approach to knowledge, rather than to its justification.
} 
speech community as general cultural knowledge or, more generally, that the source of information is unimportant to the establishment of the validity of the information.

(Mushin 2001: 74)

The author also remarks that in conveying some content from a factual stance, the speaker does not "own up to the fact that what they are talking about is their own representation of events" (Mushin 2001: 75). In fact, if some information is assumed to be shared by everybody, the speaker's representation of it must necessarily be the same as that of his interlocutors, and so the speaker cannot be qualified as the only first-hand experiencer of a fact, for he shares this knowledge with the receiver. We have seen that one way of presenting some knowledge as shared in a conversation is by presupposing it.

The properties that tie presupposition and assertion to the two evidential meanings above described are summarized in Table 1.

\begin{tabular}{c|c|l}
\hline Strategy & \multicolumn{1}{|c|}{ Evidentiality type } & \multicolumn{1}{c}{ Speaker's attitude } \\
\hline ASSERTION & Personal experience evidentiality & $\begin{array}{l}\text { The speaker presents himself as } \\
\text { the only source of the asserted } \\
\text { state of affairs and he is the one to } \\
\text { commit to its truth. }\end{array}$ \\
\hline PRESUPPOSITION & Factual evidentiality & $\begin{array}{l}\text { The speaker conveys some infor- } \\
\text { mation as already part of the re- } \\
\text { ceiver's common ground } \\
\text { knowledge. Both speaker and } \\
\text { receiver commit to the truth of the } \\
\text { information negotiated. }\end{array}$ \\
\hline
\end{tabular}

Table 1: Type and function of the evidentiality encoded by presupposition and assertion

Mushin remarks that in taking on a personal experience stance, the speaker's reliability is more likely to be addressed in conversation, whereas with a factual stance the same possibility is on the whole more reduced because the information at stake is presented as more widely shared (Mushin 2001: 75: "The fact that the speaker can be questioned with regard to source of information is evidence that the information is not yet "public property"). Givón (1982) outlines this challengeability parameter also as a distinctive trait of two types of propositions and highlights their compatibility with evidential marking:

(a) Propositions which are to be taken for granted, via the force of diverse conventions, as unchallengeable by the hearer and thus requiring no evidentiary justifications by the speaker.

(b) Propositions that are asserted with relative confidence, are open to challenge by the hearer and thus require - or admit - evidentiary justification. [emphases are mine].

(Givón 1982: 24)

That assertions admit evidential expressions to be placed within their syntactic domain is well illustrated by the following examples:

(9a) I assure that Jane is pregnant.

(9b) I've been told that Jane is pregnant.

(9c) It seems that Jane is pregnant. 
What makes the sentences in (9) possible is the fact that when some knowledge is only possessed by the speaker, he is free to do "anything he wants with it": he may strengthen his commitment to its truth, or all the way detach from it. This liberty is instead much more constrained with presupposition, which seems resistant to hosting either direct, conjectural or indirect evidentials within its scope:

(10a) ??When I assure Mark left for Finland, his girlfriend was studying in Rome

(10b) ??When seemingly/apparently Jane got pregnant, her parents were in London

(10c) ??It's strange that probably Andrew bought a new house

The oddity of the sentences in (10) hangs on the fact that if presupposed information is assumed to be in the common ground of both interlocutors and both are expected to believe it as true, any retraction from this stance (on the part of the speaker) would be logically inconsistent. Consequently, the likelihood of having some presupposed content challenged by the receiver is on the whole more shrinked, as it would contravene the assumption of shared belief and shared commitment established by presupposition packaging.

\section{Communicative functions and challengeability}

The other variable relevant to the present study is the type of content being packaged as presupposition or as assertion. Building on terminologies caught on in previous studies (Graham et al. 2013; Brocca/Garassino/Masia 2016), I will refer to this variable as the Communicative Function (henceforth, CF) of the presupposition or the assertion, meaning, by this, the particular intention with which some content is verbalized by the speaker. Drawing on taxonomies developed in previous works (Akshay et al. 2007, Boyd et al. 2010), the analysis will consider the following four CFs:

- ATTACK: criticism of unfavorable characteristics or flaws of a political opponent or group (Lee/Xu 2017);

- SELF-PRAISE: a positive statement about oneself or one's own policy (Dayter 2014)

- StANCE-TAKING: expression of one's position or stand on a particular issue (Evans 2016)

- NEUTRAL: message providing objective information or agenda announcements (Graham et al. 2013)

These four CFs are among the most diffused and represented in political propaganda, in both traditional and more recent means of mass communication (i. e. Facebook, Twitter, etc). In the previous section, I laid out assertion and presupposition as increasing or reducing the level of challengeability of some content. For the purpose of the analysis, the challengeability parameter will also be considered as characterizing the discursive effects of the four CFs outlined above and, precisely, the ease with which they might threaten the addressee's face (Goffman 1981) and thus trigger a critical reaction on his part. We may in this sense distinguish between a packaging-driven and a content-driven challengeability, the former inhering in the packaging properties of presupposition and assertion, the latter in the truth value of the content they carry.

\footnotetext{
${ }^{4}$ Ushchyna (2015) outlines the process of stance-taking as also concerned with mechanisms of identity construction.
} 
Recent threads of research on politicians' communicative behavior in public speeches and in microblogging (Lombardi Vallauri/Masia 2014; Brocca/Garassino/Masia. 2016) highlighted the different impact of these CFs on the receiver's "face" and personal building of ideological consensus. Lee/Xu (2017) describe Attack as zooming in on an issue on which the speaker has more credibility but on which the opponent is weaker. An attacking message thus accentuates the opponent's unfavorable characteristics and flaws, especially in the mind of those with low level of political knowledge (Lee/Xu 2017: 11). Since its raison d'être mainly involves inducing potential voters to think badly of an opponent and become convinced of the speaker's trustfulness, the strongly negative addressee-oriented character of an attacking CF is what makes it expectably more challengeable in a speech. As a matter of fact, the speaker may also lie about his opponent and smear his reputation on the basis of false information.

In their volume on politness, Brown/Levinson (1987) describe self-praise as a strongly facethreatening act because it entails a "raising of the self and a lowering of the other" (Dayter 2014: 92); therefore, in praising himself, the speaker does not care about the hearer's feelings (Brown/Levinson 1987: 67). Dayter also remarks that in self-praising, the speaker flouts Leech's Modesty Maxim (Leech 1983: 132) stating that, in order to be polite in an interaction, the speaker should "minimize the expression of praise of self and maximize the expression of dispraise of self". In the same way as Attack, also a Self-praising CF may involve untrue contents, by which the speaker manipulates the truth values of his messages to subtly instill a positive representation of himself in the voters' minds. Owing to these potential manipulatory effects, I assume the Self-praising CF to be equally challengeable, although, maybe, slightly less challengeable than Attack, this latter being more strongly impacting and threatening for a third person's reputation.

On a lower position in the challengeability scale, we can find the Stance-taking and the Neutral CFs. Stance-taking is a subjective and inter-subjective process (Bucholtz/Hall 2005) through which the politician re-affirms his own identity and adherence to the ideology of a political group. Reinforcement of one's stance on a certain issue delineates the speaker's perspective and solidifies his bond to the principles and tenets of his political party or movement. Compared to the former CFs, the persuasive effects of Stance-taking are not expected to be as far-reaching as those described above. On a priori bases, it would be odd to assume the speaker's expression of a belief or an opinion to elude some form of veracity. In fact, if this were the case, he would adopt a contradictory conversational move towards his own credibility. The Neutral function is probably the farthest from a prototypical challengeable attitude, due to its correlation with purely objective and factual contents.

Now, building on the foregoing considerations and assuming the challengeability parameter to develop in a gradient from more to less challengeable types of contents, I suggest viewing the four CFs distributed as follows:

$\begin{array}{ccc}\text { Attack } & \text { Self-praising } & \text { Stance-taking } \\ & \text { CHALLENGEABILITY }\end{array}$


The predictions for the present study can therefore be framed as an inversely proportional relation between the packaging and the content levels of the challengeability parameter. In this sense, more challengeable CFs (Attack, Self-praise) are expected to be encoded by a less challengeable packaging strategy, namely presupposition, carrying meanings of factual evidentiality. Conversely, less challengeable CFs (Stance-taking, Neutral) are expected to find encoding in a more challengeable packaging strategy, i. e. assertion, codifying a personal experience type of evidentiality. The reason for predicting this scenario is that the speaker can be thought to feel less confident in committing to information which he knows that might be doubtful about his own reputation or that of his opponent. In fact, he may deliberately lie in boasting himself (by, say, highlighting potentially untrue positive qualities about himself or his own party) as well as in attacking other people (e. g. stating untrue facts about their policy and future programmes), yet opt for conversational moves that render the detection of such lies and attacks less straightforward: he presupposes it because, in this way, he presents it as if it is already known by the receiver, thereby discouraging any attempt at addressing their veracity. In a different way, the politician may be expected to devote assertive strategies to the encoding of stance-taking and neutral CFs because, as already said, these functions are more weakly tendentious and less likely to involve doubtful contents. As a matter of fact, the speaker hardly has something to lose in simply stating his own opinion on something or in reporting factual information; so, he feels more confident in adopting a committal attitude towards the purpose of his message. This packaging-content challengeability interaction is better illustrated in Figure 1.

Challengeability (CONTENT LEVEL)

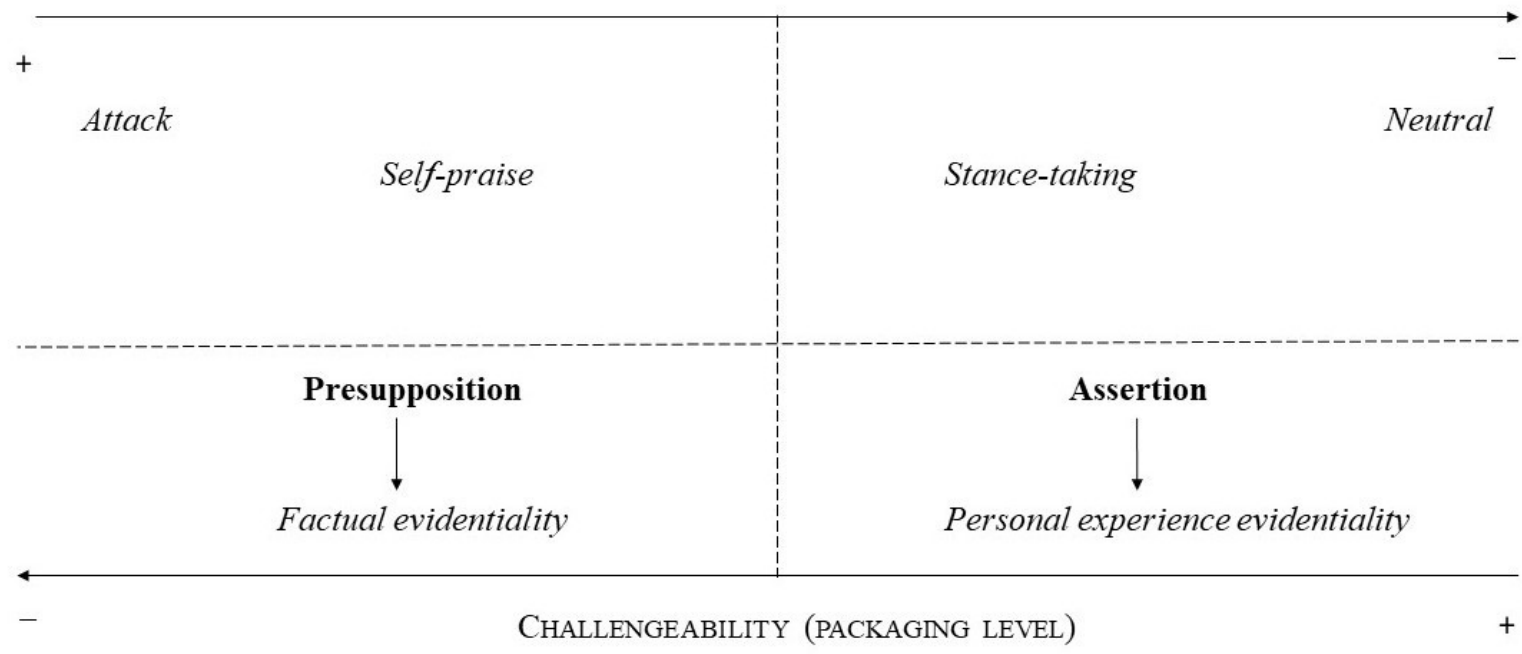

Figure 1: Interactions between levels of content challengeability and packaging challengeability

The opposing direction of the two clines indicates that an increase in the challengeability degree of a CF corresponds to a decreasing challengeability of the packaging strategy, and vice versa. If our predictions are correct, we should expect these trends to be confirmed by our results.

\section{$4 \quad$ Research questions and methodology}

\subsection{Corpus}

As anticipated in the outset, the analysis aims to gauge politicians' use of presupposition and assertion, namely, of more or less challengeable packaging strategies, in association with more 
or less challengeable CFs. For the study, 37 texts have been collected for a total amount of 102.211 words.

The corpus includes speeches from the U. S., French and Italian campaigns held between 2014 and 2017. For each language and country, two political leaders have been considered: Barack Obama and Hillary Clinton for the U. S., François Hollande (Parti Socialiste) and Marine Le Pen (Front National) for France, and Matteo Renzi (Democratic Party) and Matteo Salvini (The League) for Italy (see Table 2).

\begin{tabular}{|c|c|c|}
\hline Country & Politicians & Extension (n. words) \\
\hline U. S. A. & $\begin{array}{c}\text { Barack Obama } \\
\text { Hillary Clinton }\end{array}$ & 31.274 \\
\hline France & $\begin{array}{c}\text { François Hollande } \\
\text { Marine Le Pen }\end{array}$ & 36.167 \\
\hline ITALY & $\begin{array}{c}\text { Matteo Renzi } \\
\text { Matteo Salvini }\end{array}$ & 34.770 \\
\hline Total & & $\mathbf{1 0 2 . 2 1 1}$ \\
\hline
\end{tabular}

Table 2: Composition of the corpus

For assertions, the region of interest coincides with a full-fledged independent proposition, whereas for the presupposition packaging type, all information encoded within the trigger syntactic domain has been taken into account. Some examples will clarify this criterion.

\section{REGIONS OF INTEREST FOR PRESUPPOSITION ${ }^{5}$}

a. [When the other side refuses to compromise]PRES, progress can stall. (Obama 2016)

b. I believe that here in America our success should depend on [the strength of our work ethic.]PRES

(Obama 2016)

c. Let's continue that progress with a smarter tax policy that [stops giving $\$ 4$ billion a year to fossil fuel industries that don't need it.]PRES

(Obama 2014)

d. Ecco perché, quando sento parlare di mafia, [con la leggerezza con cui anche questa mattina è risuonata questa parola]PRES, avverto un brivido di dolore.

(Renzi 2014)

['This is why, when I hear talking about mafia, with the superficiality with which also this morning this word resounded, I have thrills of hurt']

e. L'occasion est trop belle pour ne pas, aujourd'hui, rendre hommage aussi à travers elles à toutes les femmes de France qui, aujourd'hui, se lèvent pour [continuer ce combat lumineux de la transmission et de l'amour de la Nation]PRES (Le Pen 2015) ['The occasion is too beautiful to not pay tribute, also through them, to all women of France who, today, raise to keep on with this struggle of transmission and love of the Nation']

\footnotetext{
${ }^{5}$ The bold-typed expressions indicate the presupposition triggers within the whole sentence portion which it includes.
} 


\section{REGIONS OF INTEREST FOR ASSERTION}

f. [Noi siamo abituati a confrontarci in modo non formale.]ASS

(Renzi 2014)

'We are used to talk to each other in an informal way'.

g. [Our economy isn't working the way it should.]ASS

(Clinton 2016)

h. [43 million workers have no paid sick leave.]ASS

(Obama 2015)

i. Ils sont le fait d'une armée djihadiste, le groupe Daech qui nous combat parce que [la France est un pays de liberté.]ASS

(Hollande 2015)

'It is a jihadist army, the Daech group, that we fight, because France is a country of freedom'

\subsection{Annotation and computation criteria}

With the methodological premises set out in the previous section, the first step in the analysis involved annotating all speeches according to the Packaging strategy (presupposition or assertion) used and the Communicative Function (CF) performed (Attack, Self-praise, Stance-taking, Neutral). Before going into the details of the methodology, a few preliminary remarks are in order. Given the different length of the speeches and the variety of communicative styles exhibited by the politicians, the total number of attacking, self-praising, stance-taking and neutral contents turned out to be not uniform. As a matter of fact, throughout the gathered corpus, some politicians expressed a greater amount of given content types than other politicians, independently of the topic being tackled. So, to avoid biases due to unbalanced datasets, 300 tokens have been selected for each $\mathrm{CF}$, for a total of 1.200 occurrences. Moreover, with a view to preventing a random selection from possibly favouring some CFs to the detriment of others, the occurrences have been singled out in the same order as they appeared in the discourses examined, irrespective of the packaging strategy they instantiated. Because of the variety of topics and contexts in which the speeches have been held by the politicians, the distribution and concentration of $\mathrm{CF}$ items is obviously uneven throughout the 37 discourses considered, therefore a progressive extraction could preserve a reasonable level of objectivity in the construction of the 1.200-item corpus. To ensure that all political characters were equally represented, $200 \mathrm{oc}-$ currences each (50 per CF) have been taken. The final corpus thus appears structured as in Table 3.

\begin{tabular}{|c|c|c|c|c|c|c|c|c|c|c|}
\hline \multirow[b]{2}{*}{$\mathbf{C F}$} & \multicolumn{2}{|c|}{ U. S. A. } & \multirow{2}{*}{$\begin{array}{c}\text { Total } \\
\text { CFs } \\
\text { country }\end{array}$} & \multicolumn{2}{|c|}{ FRANCE } & \multirow{2}{*}{$\begin{array}{l}\text { Tot. CFs } \\
\text { country }\end{array}$} & \multicolumn{2}{|c|}{ ITALY } & \multirow{2}{*}{$\begin{array}{l}\text { Total } \\
\text { CFs } \\
\text { country }\end{array}$} & \multirow{6}{*}{$\begin{array}{c}\text { Total } \\
\text { CFs }\end{array}$} \\
\hline & $\begin{array}{l}\text { Barack } \\
\text { Obama }\end{array}$ & $\begin{array}{l}\text { Hillary } \\
\text { Clinton }\end{array}$ & & $\begin{array}{l}\text { François } \\
\text { Hollande }\end{array}$ & $\begin{array}{l}\text { Marine } \\
\text { Le Pen }\end{array}$ & & $\begin{array}{c}\text { Matteo } \\
\text { Renzi }\end{array}$ & $\begin{array}{l}\text { Matteo } \\
\text { Salvini }\end{array}$ & & \\
\hline Attack & 50 & 50 & 100 & 50 & 50 & 100 & 50 & 50 & 100 & \\
\hline $\begin{array}{l}\text { Self- } \\
\text { praise }\end{array}$ & 50 & 50 & 100 & 50 & 50 & 100 & 50 & 50 & 100 & \\
\hline $\begin{array}{l}\text { Stance- } \\
\text { taking }\end{array}$ & 50 & 50 & 100 & 50 & 50 & 100 & 50 & 50 & 100 & \\
\hline Neutral & 50 & 50 & 100 & 50 & 50 & 100 & 50 & 50 & 100 & \\
\hline Totals & 200 & 200 & 400 & 200 & 200 & 400 & 200 & 200 & 400 & $\underline{1.200}$ \\
\hline
\end{tabular}

Table 3: Distribution of the items of CFs forming the final corpus

The reason for previously annotating the selected items for the packaging strategy they displayed hinges on the need to identify clear-cut boundaries for the relevant units of information. 
Owing to the high frequency of digressions, structurally incomplete sentences, incidental phrases, hesitations, etc., a preliminary annotation based on the syntactic extention of the CF expressed would have rendered the mapping of the four CFs onto specific packaging strategies a burdensome task. The presuppositions and assertions found in the corpus therefore instantiate parts of larger CF units whose boundaries were not always straightforwardly determined. What matters to the purpose of the analysis, though, is that the critical region represented by the presuppositive or the assertive construction could unambiguously be categorized as encoding a specific $\mathrm{CF}$.

As a second step in the analysis, the frequency with which attacks, self-praises, stance-taking and neutral contents received presupposition or assertion packaging has been assessed dividing the total number of presuppositive and assertive encodings of each CF by the total number of $\mathrm{CF}$ occurrences in the corpus, as illustrated in the following algorithm.

Single occurrence of $\mathrm{CF} \wedge$ pres/ass packaging strategy

Total n. of occurrences of CFs

The index resulting from this ratio thus indicates how frequently a presupposition or an assertion is used to express a given CF. For greater convenience, I will call this parameter frequency coefficient. For example, if, on a total of 150 occurrences of Attack, 53 receive presupposition packaging, this means that $35 \%$ of the attacking contents of the corpus are conveyed as taken for granted information and, correspondingly, as marked with a meaning of factual evidentiality. The remaining 97 occurrences ( $65 \%$ of the total) will be expressed assertively, that is, with a meaning of personal experience evidentiality.

\subsection{Research questions and methodology}

Building on the considerations expressed in the previous sections, the interplay of Packaging and CF is expected to be contingent on the challengeability parameter. Notably, given the twolevel challengeability outlined in Section 3, presuppositions, which encode a factual type of evidentiaity and epitomize a less challengeable discourse strategy, are predicted to associate more frequently with highly challengeable content types (Attack and Self-praise). Conversely, assertion, codifying a personal experience type of evidentiality and representing a more challengeable discourse strategy, is expected to correlate more frequently with weakly challengeable content types (Stance-taking and Neutral).

To assess the trends of the above-mentioned parameters, the frequency coefficients for all CFs in association with the two packaging strategies have been considered. As already said, this value should inform us on the degree to which the Packaging parameter correlates with the CF parameter, and, therefore, on the politician's preferred evidential and discourse strategy to encode different CFs.

\subsection{Results}

In this section, the graphicated frequency coefficients (cf. Table 4) associated to the two packaging types are reported for the whole corpus of 1.200 items (Figure 2) and for each country separately (Figures 3-5). 


\begin{tabular}{|l|c|c|}
\hline \multicolumn{1}{|c|}{ CF } & PRESUPPOSITION & ASSERTION \\
\hline Attack & 0.63 & 0.36 \\
\hline Self-praise & 0.76 & 0.23 \\
\hline Stance-taking & 0.11 & 0.89 \\
\hline Neutral & 0.15 & 0.86 \\
\hline
\end{tabular}

Table 4: Frequency coefficients for all CFs

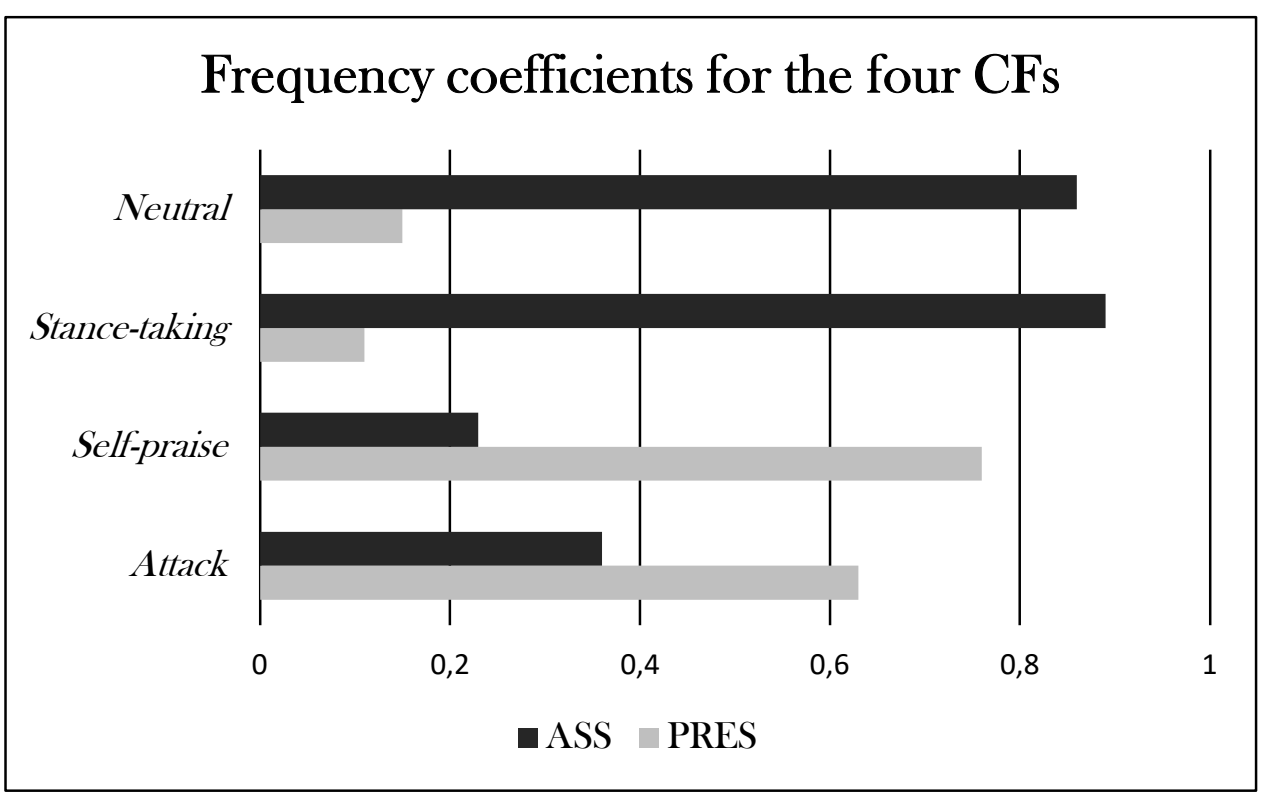

Figure 2: Frequency Coefficients of the four CFs for Presupposition and Assertion

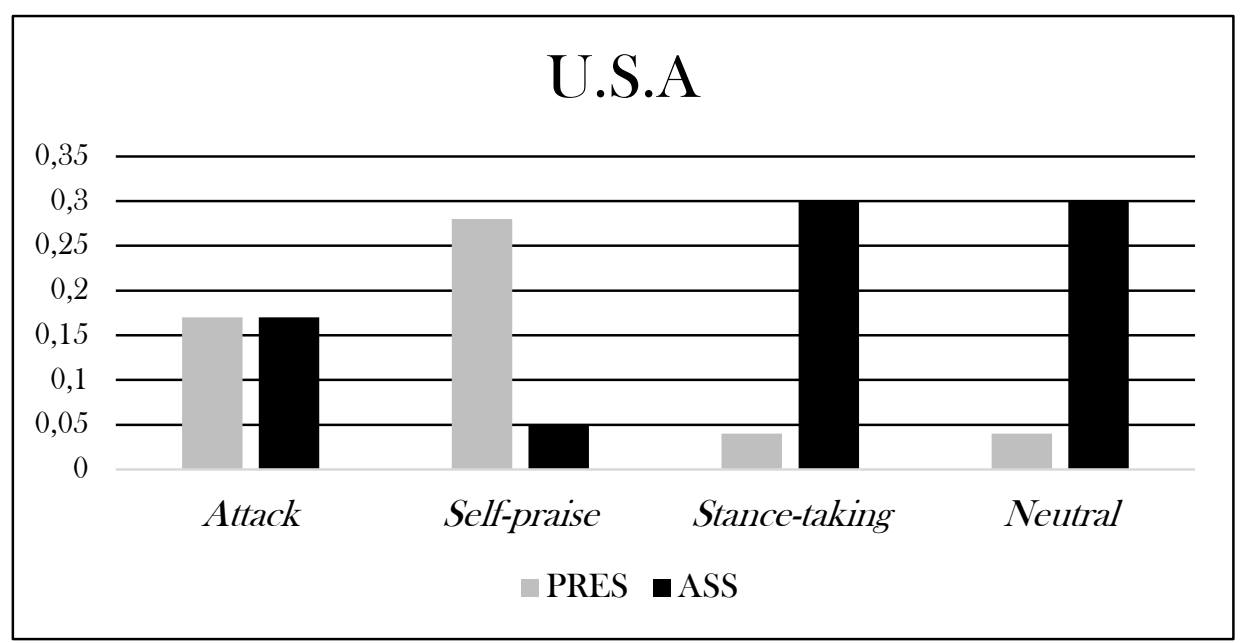

Figure 3: Frequency Coefficients for English speeches 


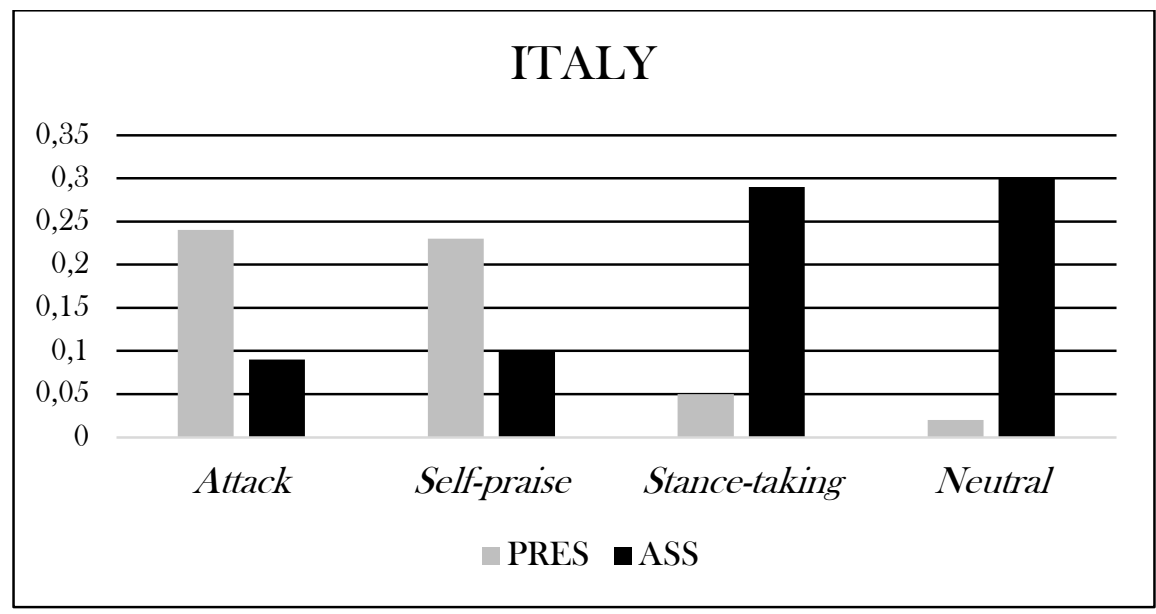

Figure 4: Frequency Coefficients for Italian speeches

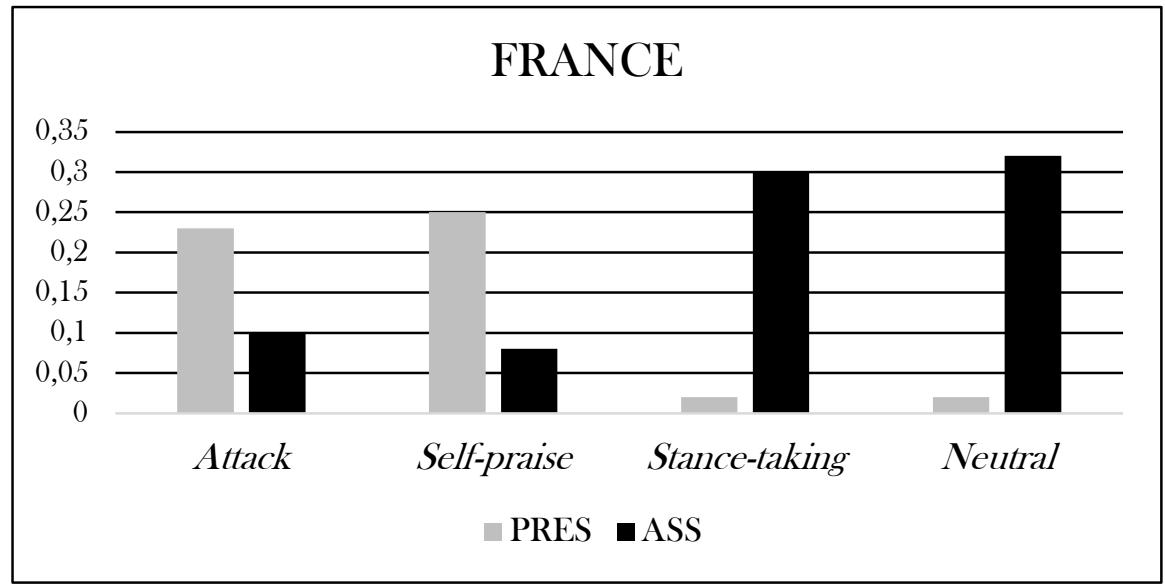

Figure 5: Frequency Coefficients for French speeches

Quite in line with our predictions, the frequency coefficients displayed in Figure 2 report a remarkable difference in the distribution of Attacking, Self-praising, Stance-taking and Neutral contents between presuppositional and assertive strategies. This observation also has a rather robust statistical support $(\mathrm{t}=4.36, \mathrm{p}$-value $=0.003){ }^{6}$

Throughout the corpus, the most widespread use of assertion is to encode Stance-taking, followed by Neutral, Attack and Self-praise. Conversely, the most frequent use of presupposition is to encode Self-praise, followed by Attack, Neutral and Stance-taking. Looking at the data gleaned for each country, these trends are particularly visible in English and French speeches, whereas for the Italian sub-corpus, presupposition seems to be more tightly associated with Attack, although with a slight difference from the CF-Packaging matching registered for Selfpraise. Three one-sample t-tests run for the datasets collected for the three countries reveal that the significance in the different distribution of presupposition and assertion packaging among the four CFs is consistent for the three countries (U. S. A.: $\mathrm{t}=4.12$, $\mathrm{p}$-value $=0.004$; Italy: $\mathrm{t}=$ 4.18, $\mathrm{p}$-value $=0.004$; France: $\mathrm{t}=3.77$, $\mathrm{p}$-value $=0.006$ )

\footnotetext{
${ }^{6}$ T-test is a type of test used in inferential statistics to determine whether the mean difference between two groups of observations is significant. A t-value greater than 2 and a p-value less than 0.05 is generally taken to point to a significant difference between the groups of means observed.
} 
An a priori consideration that can be made is that politicians are generally more leaning towards "taking for granted" contents targeted at boasting themselves, their policy or their party and towards strongly committing to contents whose function is to strengthen the speaker's ideological stance or to inform the audience about events or agenda announcements. Further remarks on the results obtained are reported in the following section.

\section{$5 \quad$ Discussion}

The purpose of the study was to inquire the evidential function of presupposition and assertion looking at the way they are used in political discourse. As is known, politicians' way of speaking is teeming with strategic conversational moves aimed at persuading the audience (Lombardi Vallauri/Masia 2014, 2016). These moves often entail perspective-taking mechanisms with corresponding modulations of commitment degrees. Proceeding from Fox's view that evidence and evidentiality are inextricably tied to political relationships among participants in an interaction (Fox 2001), I found that political discourse might serve as a suitable setting to explore how evidential meanings are built and what discourse strategies politicians resort to to convey them. The relation that the presupposition-assertion dichotomy bears on evidentiality and, precisely, on a broad type of evidentiality, has been probed assuming these two units of information packaging as marking two distinct epistemic stances in conversation and, correspondingly, two distinct types of speaker attitude evidentiality. The factual evidentiality encoded by presupposition is indicative of a more shared commitment to the truth of a proposition. We have seen that this interpretation hangs on the property of presupposition to place some information within the epistemic territory of both speaker and receiver (Heritage 2012), which makes it, so to say, "watertight" against potential addressability. As a matter of fact, in challenging a content which he also believes as true, the receiver would adopt an uncooperative and inconsistent communicative behavior. Experimental studies in the psycholinguistic domain have buttressed this addressability-resistant attitude of presuppositions (Amaral/Cummins 2015).

The frequency coefficients calculated to assess how often presupposition and assertion are used to encode specific communicative functions (CF) confirm our prediction that contents more likely to be face-threatening for the speaker or for a political rival tend to receive presuppositional encoding. Considering the evidential characterization put forward for presupposition, this trend can be thought to hinge on the shared-commitment effect triggered by presupposition. On a priori bases, in the discourses examined, the speaker seems to follow the general rule that when a content risks to smear his reputation in the opinion of his voters, it is preferable to make voters likewise responsible for the content negotiated. An efficient device to achieve this is by making them "holders" of the same content, yet without making them aware of this state of knowing. One of the reasons why presupposition can effectively serve this communicative purpose is also the impact it wields on the receiver's attentional processes. The experimental literature is nowadays abundant on the way presupposition reduces attention on some information, thereby inducing a shallow decoding of its truth (Loftus 1975, Langford/Holmes 1979, Schwarz 2015). So, in conveying some content as presupposed, not only is the speaker introducing that content in the receiver's common ground, but he is also providing him with the instruction of devoting a lesser attention to it and accept it as it is with no deeper inspection of its truth conditional meaning. As it can be easily deduced, if this has harmless repercussions for contents 
the receiver actually knows in advance, when it comes to new presuppositions, this may conceal insidious manipulatory intents (Sbisà 2007, Lombardi Vallauri/Masia 2014). Although dangerous for the construction of a well-informed electorate, this state of things is (regrettably) at the basis of persuasive propaganda worldwide. So, besides commitment degrees, the evidentiality encoded by presupposition and assertion also has remarkable (yet still under investigation) psychological correlates.

The distribution of frequency coefficients (Figure 2, Table 3) also confirms the expectation of a strong interaction between assertive packaging and weakly tendentious CFs. The low challengeability of Stance-taking and Neutral CFs in the challengeability continuum suggested has been put down to the fact that politicians are generally believed to have scant, if any, persuasive needs in simply expressing opinions (e. g. Clinton in a 2017 speech: “...we want diversity in everything we do in our country...") or agenda announcements (e. g. Obama in a 2016 speech: "I'm putting Joe in charge of mission control"). Having nothing to lose in conveying these content types, the politician feels freer to manifest her commit to their truth. Indeed, as already argued in Section 3, in lying about his own stance or fixed agenda plans, not only would the speaker appear uncooperative, but he would also look as if he is disavowing his identity as member of his political group with respect to certain ideological concerns. These two CFs seem to positively interact with the speaker and receiver's face since they are not directly targeted at either blasting somebody else or constructing tendentious ideas in voters' minds. A stronger commitment in this case would therefore not risk to abate the speaker's authority and credibility. Similarly to presupposition, also the cognitive treatment of assertion has been the object of psycholinguistic investigation. Offline and online behavioral studies (Hornby 1973, Langford/Holmes 1979, Birch/Rayner 1997) report a more effortful processing for asserted contents and a more thorough mental representation of their truth value in the receiver's mind. If, with presupposition, the epistemic condition of shared commitment has a cognitive correlate in attention-reduction - because the information is presented as already shared - with assertion, the stronger commitment manifested by the speaker is underpinned by a greater attentional effort. So, in evidential terms, the speaker's taking a personal experience stance provides the receiver with the instruction to pay greater attention to the content being conveyed.

The trends reported in Figure 2 also show that the difference between Self-praise and Attack in presupposition use is greater than the difference between Neutral and Stance-taking in the use of assertion. The general tendency of politicians to presuppose self-praises can be explained, among other things, appealing to the two-fold challengeability effect accompanying Self-praising contents. Quoting Brown/Levinson (1987), Self-praise can be thought to entail two communicative acts: one, more explicit, aimed at expressing self-flattering information; the other, more implicit, hinting at a minimization of the receiver or of other addressees. This feature of self-praising information is well illustrated by the following example from Marine Le Pen's speech:

(12) J'appelle en ce premier mai tous les patriotes de France, d'où qu'ils viennent, quel que soit leur engagement politique passé, à me rejoindre. Qu'il rejoigne le seul parti qui sait où il va, pourquoi il y va, et qui ne s'embarrasse pas de ces querelles d'égos, qui reste sur le fond des projets, qui propose une voie aux Français!

(Le Pen: 2016) 
Here, the defining relative clause le seul parti qui sait où il va presupposes that there is only one party which knows where to go. Moreover, by means of implicature, it is also inferred that this one party is the Front National and, correspondingly, that other parties so far have never known where to go.

A similar case is the following excerpt from Obama's speech:

(13) What was true then can be true now. Our unique strength as a nation, our optimism and work ethic, our spirit of discovery, our diversity, our commitment to rule of law - these things give us everything we need to ensure prosperity and security for generations to come.

(Obama: 2016)

Here, not only do the bold-typed definite descriptions presuppose that the United States have a unique strength, are optimistic, have a spirit of discovery and have a sense of commitment to rule, but the emphasis placed on the possessive adjective our also conveys the idea that all these qualities are not matched to the same degree by other countries. Also in this case, the speaker's intention to boast himself (or his country) and to downgrade the others can be retrieved via implicatural mechanisms (Grice 1975). As a matter of fact, any nation has a somewhat unique strength, different than that of other nations, and any nation had some spirit of discovery in the past. By the same token, any population is made of law-abiding citizens and people who are more prone to flout the rules. So, since Obama's persuasive intent cannot be to state mere truisms, the real informative goal underlying the utterance of those definite phrases must be that those qualities are possessed by Americans in a special and peculiar way, which makes the condition of being American something to be proud of.

The impact of presupposition on the challengeability degree of some content is also remarkable on attacking content types. Consider the (corpus) sentences in (14) and (15) and their reformulation in (14a) and (15a).

(14) Le decisions arbitraries du ministère finissent par exaspérer des professionels, qui ont l'impression qu'on essaie de les court-circuiter.

(Le Pen: 2016)

(14a) Le ministère a pris des decisions arbitraries et ceux-ci finissent par exaspérer des professionels, qui ont l'impression qu'on essaie de les court-circuiter.

(15) When Congress is dysfunctional we should draw our districts to encourage politicians to cater to common sense and not rigid extremes.

(Obama: 2017)

(15a) Congress can be dysfunctional. That's why we should draw our districts to encourage politicians to cater to common sense and not rigid extremes.

In (14), while the fact that ministeries have made arbitrary choices is treated as taken-forgranted knowledge by means of a definite description, in (14a) the same content is conveyed as a more relevant and purposeful component of the speaker's message, since, through assertive encoding, it is brought to a foregrounded position. Similarly, in (15), that Congress has been or can be dysfunctional is backgrounded and treated as secondary and already known information as compared to its assertive version in (15a), where it is verbalized as plain assertion. A straightforward effect that can be noticed from these comparisons is that, in hearing (14) and (15), the receiver is, so to say, subtly induced to restructure his mental model of discourse by tacitly accepting the fact that ministeries have made arbitrary decisions and that Congress is dysfunctional, since, in a way, presupposition surreptitiously leads him/her to take on the position of 
"knower" of those states of affairs, along with the speaker. And it is precisely this stance that prevents him from inquiring their truth. On the contrary, by hearing (14a) and (15a), the receiver more strongly perceives those contents as not belonging to his epistemic territory (otherwise the speaker would not convey them as the communicative aim of his message) and so he feels in the condition to doubt about their truth and eventually challenge it.

The frequency coefficient values of Stance-taking and Neutral contents in the use of assertion confirm the relevance of this pragmatic marker of personal experience evidentiality in the encoding of weakly challengeable information. Presupposition use appears slightly more frequent with Neutral contents, compared to Stance-taking ones. This behavior may be suggestive of the speaker's necessity to put the neutral content in the background, thus focusing some other sentence unit(s). The incidence of this conversational move is however feeble throughout the whole corpus, meaning that the speaker is more likely to increase the addressees' level of attention on contents which do not deserve an in-depth critical evaluation, whereas those whose truth is more prone to be more dubious are "passed" below the level of critical attention and are, for this purpose, presupposed.

On balance, what the results confirm is a fairly strong content-oriented use of presupposition and assertion strategies in the political speeches examined. On a priori grounds, this pattern reveals a general sensitivity of political speakers to utter their messages taking into account the effects that both the contents conveyed and the way they are packaged might produce on the recipient. So, if, in Lambrecht's terms, information structure reflects "the speaker's assumption about the hearer's state of knowledge and awareness at the time of an utterance" (Lambrecht 1994: xiii), this property seems to be less compelling in messages uttered for persuasive aims. Indeed, in these contexts of language use the achitecture of sentences' information structure does not pre-eminently look at the receiver's knowledge state, given that packaging criteria and activation states of contents often do not match in political speeches, but rather look at the receiver's potential reaction to the truth of the information conveyed.7 "Reaction" is here intended to refer to assumptions of credibility, evaluation of trustfulness, the speaker's honesty and addressability in case of contents of dubious veracity. The way receivers handle these aspects of their interactional behavior will determine the extent to which the speaker's reputation risks to be smeared or damaged. In order to keep this risk under control, the speaker might benefit from reducing any chance to be addressed for what he says and, at the same time, achieve her/his manipulative intent of "injecting" ideas in the receiver's mind. These epistemic/evidential properties of information structure is what makes it an effective strategy to get

\footnotetext{
${ }^{7}$ As rightfully noticed by Sbisà (2007), public communicators often do not care about whether certain contents will be easily reconstructed by the receiver. What rather seems to matter to them is that the text/discourse is "usable" as it is (Ibid: 14: "l'effettiva ricostruibilità di un senso da parte dei fruitori è l'ultimo pensiero da parte dei comunicatori e a questo punto, forse, dei fruitori stessi. Se qualunque testo, purché apparentemente coeso, può ricevere nella fruizione qualunque senso - basta che sia usato, consumato - non occorre certo darsi pena, né che sia comprensibile, né che contenga effettivamente qualche cosa da comprendere; né occorre darsi pena di comprendere questo qualcosa.", English translation: "The retreadability of a content on the part of text users is the last thing on communicators' minds and, maybe, also the last thing for the users themselves. If any text, although apparently cohesive, can be used in some way - as long as it is used and read - there is no need to bother for its understandability, nor for the presence of anything to be understood, nor is there any need to worry about understanding this something.").
} 
messages across and easily convince receivers of their veracity as well as of the speaker's reliability.

Needless to say, the foregoing considerations could certainly benefit from extending the proposed research to a wider corpus of political speeches, hopefully selected according to a more systematic balancing of parameters such as topic, context, political group, year, etc. Added to this, more fine-grained methodologies of descriptive and inferential statistics would no doubt clarify the scenario emerged from the analysis and reveal more straightforward and sharply defined patterns of interactions between the presupposition-assertion level and the types of content they encode. This contribution then wishes to be a first gambit in the direction of gathering and delving into more telling pieces of evidence of the relation between evidentiality and information structure.

\section{Conclusion}

What this study sought to demonstrate is that the presupposition and assertion of contents may have evidential purposes. The evidentiality encoded by these two strategies of information packaging is of a broad type (Chafe/Nichols 1986), as it entails different degress and strengths of manifestation of the speaker's commitment to truth. I have proposed to appraise this evidential facet with relation to specific types of content in political speech in which the use of presupposition and assertion appears to be remarkably sensitive to the challengeability of the content they encode. In the corpus considered for the analysis, the discourse strategies adopted by politicians reveal an inverse relation between the challengeability associated with presupposition and assertion packaging and that stemming from the content being conveyed. Due to the underdeveloped research on information structure and evidentiality encoding, a more exhaustive account of the data gleaned from the present inquiry certainly calls for fine-tuning the methodology put to test and extend it to other domains of language use.

\section{References}

Aikhenvald, Alexandra Y. (2004): Evidentiality. Oxford: Oxford University Press.

Akshay, Java et al. (2007): "Why We Twitter: Understanding Microblogging Usage and Communities". Paper presented at the Joint 9th WEBKDD and 1st SNA-KDD Workshop.

Amaral, Patricia/Cummins, Chris (2015): “A cross-linguistic study on information backgrounding and presupposition projection”. In: Schwarz, Florian (ed.): Experimental perspectives on presuppositions. Dordrecht: Springer: 157-172.

Birch, Stacy/Rayner, Keith (1997): Linguistic focus affects eye movements during reading. Memory \& Cognition 25/5: 653-660.

Boas, Franz (1900): "Sketch of the Kwakiutl language". American Anthropologist 2: 708-721. Boas, Franz (1910): Kwakiutl. An illustrative sketch. Washington: Government Printing Office.

Boyd, Danah/Golder, Scott/Lotan, Gilad (2010): “Tweet, tweet, retweet: conversational aspects of retweeting on Twitter". In: Proceedings of the 43 Hawaii International Conference on System Sciences. IEEE Computer Society. Los Alamitos, CA: 1-10.

Brocca, Nicola/Garassino, Davide/Masia, Viviana (2016): "Politici nella rete o nella rete dei politici? L'implicito nella comunicazione politica italiana su Twitter". PhiN-Beiheift 11/2016: 66 . 
Brown, Penelope/Levison, Stephen C. (1987): Politeness: Some Universals of Language Use. Cambridge: Cambridge University Press.

Bucholtz, Mary/Hall, Kira (2005): "Identity and interaction. A sociocultural linguistic approach". Discourse Studies 7/4-5: 585-614.

Chafe, Wallace/Nichols, Joanna (eds.) (1986): Evidentiality: The linguistic coding of epistemology. Norwood, NJ: Ablex.

Cornillie, Bert (2009): "Evidentiality and epistemic modality. On the close relationship between two different categories". Functions of Language 16/1: 44-62.

Cresti, Emanuela (1987): "L'articolazione dell'informazione nel parlato". In: Incontri del Centro di Studi di Grammatica Italiana. Gli italiani parlati. Sondaggi sopra la lingua di oggi. Firenze, Accademia della Crusca: 27-90.

Dayter, Daria (2014): “Self-praise in micro-blogging”. Journal of Pragmatics 61: 91-102.

Dummett, Michael (1981): Frege: Philosophy of language. $2^{\text {nd }}$ ed. Cambridge: Harvard University Press.

Evans, Ash (2016): "Stance and Identity in Twitter Hashtags". Language@Internet, urn:nbn:de:0009-0-54947. [06.07.2018]

Faller, Martina T. (2002): Semantics and pragmatics. University of Stanford, Department of Linguistics: Ph.D. Dissertation thesis. personalpages.manchester.ac.uk/staff/martina.t.faller/documents/Thesis-A4.pdf. [06.07.2018]

Faller, Martina T. (2011): "A possible worlds semantics for Cuzco Quechua evidentials". In: Lutz, David/Li, Nan (eds.): Proceedings of Semantics and Linguistic Theory 20. Ithaca, NY: CLC Publications.

Fillmore, Charles J. (1971): "Verbs of judging: An exercise in semantic description". In: Fillmore, Charles J./Langendoen, Terence D. (eds.): Studies in linguistic semantics. New York: Holt-Rinehart and Winston: 272-289.

Fox, Barbara A. (2001): "Evidentiality, authority, responsibility, and entitlement in English conversation". Journal of Linguistic Anthropology 11/2: 167-192.

Friedman, Victor A. (1986): "Evidentiality in the Balkans. Macedonian and Albanian". In: Chafe, Wallace/Nichols, Joanna (eds.): Evidentiality: The linguistic coding of epistemology. Norwoord, NJ, Ablex: 168-187.

Givón, Talmy (1982): “Evidentiality and epistemic space”. Studies in Language 6: 23-49.

Goffman, Erving (1981): Forms of talk. Philadelphia: University of Pennsylvania Press.

Graham, Todd et al. (2013): "Betweet broadcasting political messages and interacting with voters. The use of Twitter during the 2010 UK general election campaign". Information, Communication \& Society 16(5): 692-716.

Grice, Paul H. (1975): “Logic and conversation”. In: Cole, Peter/Morgan, Jerry L. (eds): Syntax and semantics 3: Speech acts. New York, Academic Press: 41-58.

Gundel, Jeanette K./Fretheim, Thorstein (2004): "Topic and Focus". In: Horn, Laurence R./Ward, Gregory (eds.): The Handbook of Pragmatics. UK, Blackwell: 175-196.

Heritage, John (2012): "Epistemics in Action: Action formation and territories of knowledge". Research on Language and Social Interaction 45/1: 1-29.

Hornby, Peter A. (1973). "Intonation and syntactic structure in the development of presupposition". Paper presented at the biennial meeting of the Society for Research in Child Development. Philadelphia, Pennsylvania: 18f. 
Kiparsky, Carol/Kiparsky, Paul (1971): "Fact”. In: Steinberg, Danny D./Jakobovitz, Leon A. (eds.): Semantics: An Interdisciplinary Reader. Cambridge, Cambridge University Press: 345-369.

Lambrecht, Knud (1994): Information structure and sentence form. Cambridge: Cambridge University Press.

Langford, John/Holmes, Virginia, M. (1979): "Syntactic presupposition in sentence comprehension". Cognition 7: 363-383.

Lee, Jayeon/Xu, Weiai (2017): “The more attacks, the more retweets: Trump's and Clinton's agenda setting on Twitter”. Public Relations Review, doi: 10.1016/j.pubrev.2017.10.002.

Leech, Geoffrey (1983): Principles of Pragmatics. London: Longman.

Lewis, David (1979): "Scorekeeping in a language game". Journal of Philosophical Logic 8/3: 339-359.

Loftus, Elizabeth F. (1975): "Leading questions and the eyewitness report". Cognitive Psycho$\log y$ 7: 560-572.

Lombardi Vallauri, Edoardo (2009): La struttura informativa. Forma e funzione negli enunciati linguistici. Carocci: Roma.

Lombardi Vallauri, Edoardo (2016): "Implicits as Evolved Persuaders". In: Allan, Keith/Capone, Alessandro/Kecskes, Istvan (eds.): Pragmemes and Theories of Language Use. Perspectives in Pragmatics, Philosophy and Psychology. Switzerland, Springer: 725-748.

Lombardi Vallauri, Edoardo/Masia, Viviana (2014): "Implicitness impact: measuring texts". Journal of Pragmatics 61: 161-184.

Lombardi Vallauri, Edoardo/Masia, Viviana (2016): "Specificità della lingua persuasiva: 1'implicito discutibile”. In: Ruffino, Giovanni/Castiglione, Marina (eds.): Lingua variabile nei testi letterari, artistici e funzionali contemporanei. Analisi, interpretazione, traduzione. Firenze, Cesati: 637-654.

Masia, Viviana (2017a): Sociobiological Bases of Information Structure. Amsterdam/Philadelphia: Benjamins.

Masia, Viviana (2017b): "On the evidential account of presupposition and assertion". International Journal of Linguistics 9/4: 134-153.

Mazzarella, Diana et al. (2018). "Saying, presupposing and implicating: How pragmatics modulates commitment". Journal of Pragmatics, 133: 15-27.

Murray, Sarah E. (2010): Evidentiality and the structure of speech acts (PhD Dissertation). New Jersey, University of New Jersey.

Mushin, Ilana (2001): Discourse analysis: Evidentiality and epistemological stance. Narrative retelling. Amsterdam/Philadelphia: Benjamins.

Saussure de, Louis (2011): "Discourse analysis, cognition and evidentials". Discourse Studies I/65: 32-39.

Sbisà, Marina (2007): Detto non detto. Le forme della comunicazione implicita. Roma-Bari: Laterza.

Searle, John (1969): Speech acts: An essay in the philosophy of language. Cambridge: Cambridge University Press.

Stalnaker, Robert C. (1978): “Assertion”. In: Cole, Peter (ed.): Syntax and semantics. Pragmatics 9. New York, Academic Press: 315-332. 
Schwarz, Florian (2015): "Presuppositions vs. Asserted content in online processing". In: Schwarz, Florian (eds.): Experimental perspectives on presupposition. Studies in theoretical psycholinguistics. Dordrecht, Springer International Publishing: 89-108.

Ushchyna, Valentyna (2015): "Epistemic stance and the linguistic realization of expert identities in risk communication". In: Boguslawska-Tafelska, Marta/Drogosz, Anna. (eds.): Towards the Ecology of Human Communication. Cambridge, Cambridge Scholars Publishing: 33-50.

Vanderveken, Daniel (1990): Meaning and Speech Acts: Principles of Language Use. Vol. 1. Cambridge: Cambridge University Press.

Willett, Thomas (1988): “A Cross-Linguistic Survey of the Grammaticalization of Evidentiality". Studies in Language 12/1: 51-97.

\section{Annex}

\section{List of Abbrviations}

$1 \quad$ First person subject

$2 \quad$ Second person subject

$3 \quad$ Third person subject

1P First person possessor

ACC Accusative

ASS Assertion

CAUS Causative

DIR Direct

EMPH Emphatic

EVID Evidential

GEN Genitive

IMPRF Imperfective

INFER Inferential

NAR Narrative

NEG Negation

PRES Presupposition

PL Plural

PLUPRF Pluperfect

PROG Progressive

PST Past

REFL Reflextive

REPORT Reportative 